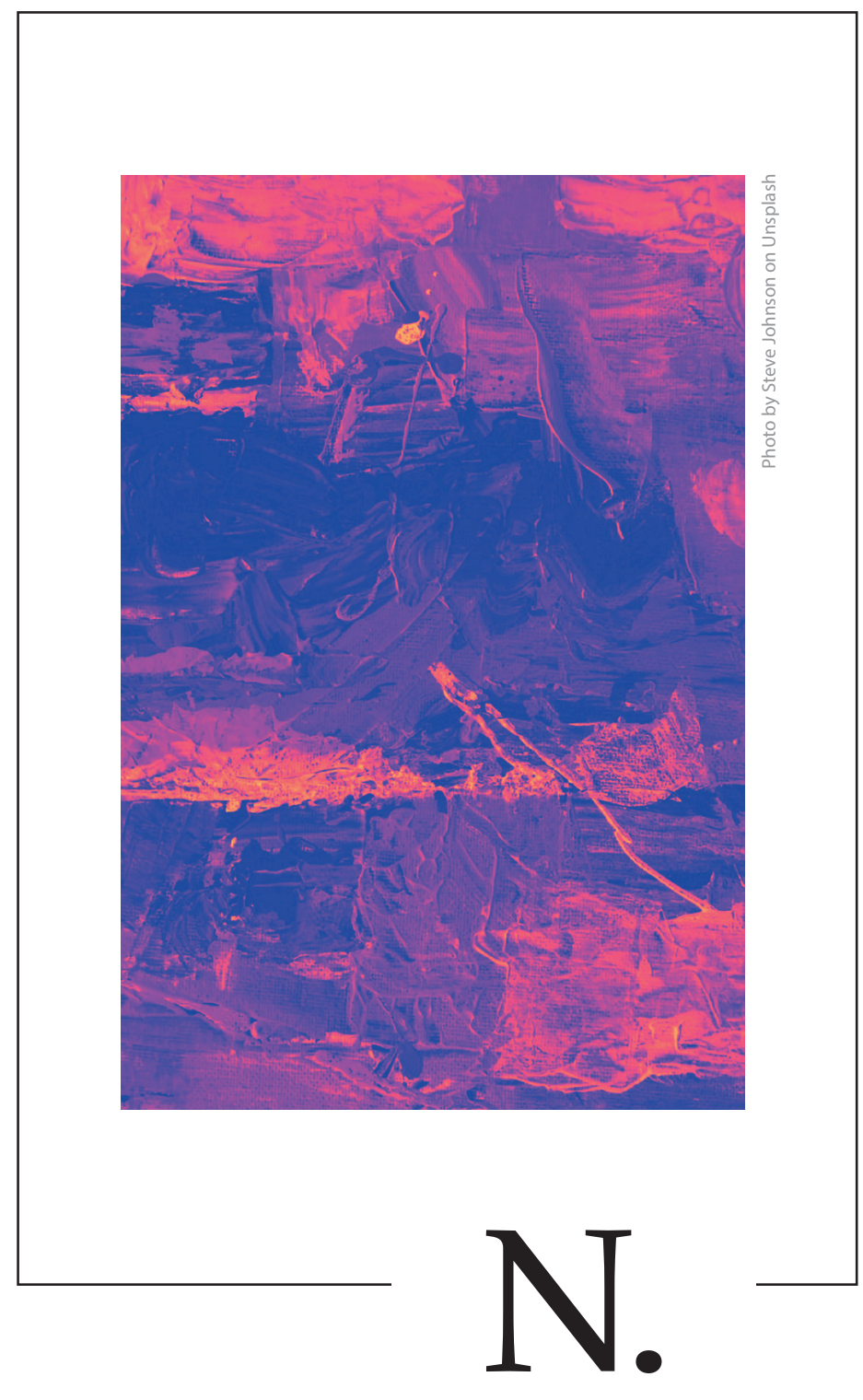

NARRATIVA 


\section{Diario de la servidumbre}

FERNANDO IRIARTE

\section{EL CIELO DE LAS CIUDADES}

Nos miran los días malos y los días de superación, extienden sus miradas rendidas a la pulcritud. A veces se las devuelves abriéndote paso entre lo que queda del cansancio, cuando por casualidad entregan una rendija o un poco de aire contenido, o cuando separan demasiado los abrazos. Un solo y tibio instante, para nada: por la fuerza de algún recóndito malestar, intentas sostener la falsedad, de tú a tú, y por supuesto pierdes al reconocerla de antemano. A pesar de ese pequeño teatro, saben contestar y hasta procuran el simulacro de la persuasión desde sus sonrisas enormes. Es inútil recriminarle apatía a un muerto.

La mano detrás de esos cuerpos no existe. La supuse durante mucho tiempo y postulé uno que otro nombre, superficial como la promoción de cualquier ídolo. Existe, en cambio, el adiestrador de ojos. El dispensador de luces y sombras. El tipógrafo. El decorador. Poderosos e invisibles para cualquier defecto, han mentido esgrimiendo una gran verdad: se puede vivir consistentemente de lo que no se es. A ciegas, nos han educado desde sus redundancias, en íntima discontinuidad.

Ellos trabajan a diario - hasta y sobre todo los domingos- y nuestras expresiones tienden a su imagen por la semejanza. Nadie luce los dientes tan blancos ni la piel tan pura, ni amaga saludos tan insignificantes. Nadie se divierte ahora -aunque el vacío existe y envejece en muchas cabezas-. Se necesita una lista de espera y, solo después, los nacimientos.

Del otro lado estamos nosotros, escudriñándolos, revelando un proceder mecánico para servir cada vez menos. 


\section{SOBRE LAS ÍES}

Estábamos jugando fútbol a la salida del trabajo y Leandro se cayó de cabeza tras disputar la pelota en una jugada en ataque con la que de todas maneras íbamos a cerrar el partido. Leandro es volante por defecto: lento para defender y muy malo para definir; le decíamos siempre: recibe el balón y busca al delantero; cuando se recuesten por donde estás, al menos estorba. Casi siempre atacábamos por el otro costado, pero ese poco que le encomendábamos a Leandro lo hacía más o menos bien. A veces sus pases eran pases de gol. Esa tarde cambió de lugar con el punta, un gordito que reemplazaba a nuestro ariete habitual. Tal vez Leandro se confió o tal vez solo fue verse un poco mejor que el nuevo. El asunto es que le llegó un centro cuando el partido estaba por terminar y Leandro saltó para alcanzar la pelota. Saltó alto, muy alto. Y el central que lo estaba cubriendo más bien se agachó y Leandro pasó por encima de su marca y cayó de cabeza. La caída nos dolió a todos, incluso a los que no la vieron, pero sí la escucharon. El golpe seco y el crujido. Yo estaba caminando justo detrás de él y lo primero que hice fue pararme al lado de Leandro a esperar que abriera los ojos. Alguien gritó: “iNo lo muevan!" y me intimidó en varios niveles. Ya estábamos todos a su alrededor cuando se me pasó un poco el susto. Leandro seguía con los ojos cerrados y rígido. Resultó que entre nosotros había un doctor. Dijo que Leandro parecía muerto. Llamé a Mariana, su mujer, por encargo del capitán del equipo. Yo era el menos indicado para hacerlo. Pensé una y otra vez en la palabra muerto. Lo que ella me respondió cuando le conté lo que había pasado, después de un larguísimo silencio - que en ese momento interpreté como un acto solemne, pero que ahora sé que se trataba de cualquier otra cosa-, fue: “Qué, otra vez?”.

2

Leandro no estaba muerto, pero lo internaron en una clínica durante mucho tiempo y pasó en casa otro tanto. En total, hablamos de semanas. Cuando regresó a la oficina llevaba un collarín y caminaba serio y en silencio, como si en parte nos culpara de lo ocurrido el día del accidente. Yo necesitaba hablar con él, pero al mismo tiempo temía que me esquivara, que me dejara con la palabra en la boca. Es una de las situaciones sociales que más temo: hablar y que no me respondan y se vayan, o hablen con otra persona, aniquilándome. Por descuido o a propósito, aunque la segunda posibilidad me asusta mucho más. Así que esperé a que estuviera solo. Lo observé durante días y 
supe que el mejor momento para abordarlo era exactamente cuando se paraba a beber agua del bidón del corredor, después del refrigerio, momento en que la mayoría de colegas se acumulaban en el baño o se encaminaban a sus escritorios, de vuelta a las faenas diarias. "Hola, Leandro", le dije, como si no nos hubiéramos saludado temprano. Inclinó la cabeza y se acabó el agua del vaso. Necesito hacerte una pregunta. Mira, el día del accidente - Leandro juntó toda su molestia entre las cejas- llamé a Mariana para contarle lo que pasó. Y su respuesta fue... Bueno. A ella casi no le importó. Desde ese día he estado pensando. No he dejado de pensar en eso, la verdad. He estado pensando qué tiene que hacerle un hombre a una mujer para que a esta no le importe si él está vivo o muerto. Eso.

En algún momento de la vida vas a conocer a alguien que hace las mismas cosas que tú después de enterarse de que las has hecho. Parece desesperante, precisamente porque lo es. Pero se trata del producto de la admiración. No puede ser tan negativo. Alguien en la oficina entendió que yo me había acercado a Leandro para arreglar las cosas entre los muchachos y él, todo eso que se había roto con la caída. En los días sucesivos a nuestra conversación frente al bidón de agua, mis compañeros empezaron a replicar mi comportamiento, uno por uno, en el mismo lugar y justo en el lapso del día que mis investigaciones informales habían establecido como aquel momento cuando Leandro bajaba la guardia. Primero los intercambios parecían meras prolongaciones de un saludo. Pero con las semanas fueron creciendo en palabras, en sentido y hasta en emoción. Una vez que intenté escuchar lo que hablaban recogí expresiones como "es el mismo material con el que yo construí mi casa". A veces, incluso, se escuchaban risotadas y apuestas sobre los partidos de fútbol del fin de semana.

Es extraño. Lo es, porque lo que ocurrió aquella tarde frente al bidón fue más bien decepcionante para mí. Como respuesta a mi pregunta, Leandro se había limitado a pedirme que me ocupara de mis asuntos. Lo hizo de una manera tajante y grosera. $\mathrm{Y}$ aunque el resultado de sus palabras fue enteramente el contrario -llamé a Mariana varias veces más para preguntarle su opinión sobre lo que me inquietaba; con el tiempo nos hicimos un poco más que amigos-, no hablé más con él. De hecho, no volví a jugar fútbol con los muchachos, que retomaron los partidos con el mismísimo Leandro, a juzgar por lo que logré entender, alguna vez, de aquellas charlas frente al bidón. 


\section{MENTIRAS, INSTRUCCIONES DE USO}

ma vie dernier état mal dite mal entendue mal retrouvée mal murmurée

Samuel Beckett

Mi padre me dijo:

El diablo, que es una serpiente (que es una mentira), empieza a enredarse desde lo más bajo que encuentre, acaba primero con las libertades mínimas y continúa sin detenerse hasta que para uno solo es posible mirar de reojo cualquier final, casi ahogado... y, sin embargo, en ese momento, ya sin nombre, por fin se respira algo de verdad. Porque comenzó así, con una etiqueta que tuviste que aprender a recordar. Te llamas tal. Repites: tal o cual. Darse por enterado también de eso. Tal o cual. Así comienza todo.

No estábamos en su lecho de muerte, ni mucho menos. Acabábamos de jugar un partido de fulbito y se envalentonó, sospecho, por los dos muy buenos goles que nos permitieron perder con dignidad. De viejo, lo único que le relajaba el perfil era la pelota. La pelota y la cerveza.

Están también los nombres de los demás, donde la pieza de tales y cuales letras habrá de encajar; sí, los demás, que seguro han sabido mentir mejor que tú, siempre queda esa sensación, y cuando les preguntas por qué te dicen que su escuela ha sido la vida.

Además de futbolero (recién colgó los chimpunes bien pasados los sesenta), mi padre era un magnífico orador que dedicó gran parte de su vida a manejar públicos inmensos en reemplazo de los lectores que siempre le fueron esquivos: su única novela publicada, de muy leves méritos artísticos, fue engullida con crueldad por una contundente indiferencia, y las compilaciones de sus discursos públicos se vendían poco para los estándares del subgénero al que pertenecían, casi siempre a la salida de auditorios repletos de apasionados por el coaching ontológico.

La buscarás hasta el final, valiente o estúpido. Quién sabe, acaso allá en la vida uno aprende sobre todo a mentir como se debe. Pero el camino será más o menos el mismo, se multiplicarán las etiquetas, y el vertiginoso número que las abarca, lejos de producirte escalofríos y náusea, te acercará poco a poco hacia algún tipo de olvido; con suerte, hacia una sonrisa maquinal.

Recuerdo también cuando le confesé que quería ser escritor. Él estaba hablando por teléfono e hizo con la mano, con el pulgar y el índice de la mano libre, un gesto que significaba que yo debía esperarlo un momento. Sentado en su sofá verde, en un instante lo entendí como si fuera el juez de la eternidad. Me fui corriendo a mi habitación 
a mirar los pósteres a los que ya no les quedaba mucho tiempo más en esas paredes adolescentes.

Ya viejo, si me permites esta última tergiversación, una tarde sin sol cualquiera, una tarde sin sol cualquiera no te parecerá una tarde sin sol cualquiera.

Desde luego que sabía que mi padre había intentado ser escritor cuando joven. Con frecuencia en la sobremesa él nos hablaba a mi hermana y a mí sobre sus épocas universitarias, y ese libro fue la mejor manera que encontró para concluirlas. Eso sentenciaba y a nosotros nos tocaba creerle. No conservaba un solo ejemplar de la novela en casa. Mucho tiempo después encontré uno en la enésima biblioteca municipal en la que me atreví a buscarlo, lo pedí prestado y no lo devolví.

Cerrarás los ojos. Te acordarás de mí y de estas palabras que no alcanzo a decir en el recto sentido. $Y$ todo te parecerá un mal sueño.

Yo destapé la tercera o cuarta cerveza y le dije salud, por tanta inspiración. Me respondió salud y me miró a los ojos y yo supe que quería preguntarme algo. ¿Por mi más reciente libro, por la beca que me llevaría lejos, sabe Dios cuánto tiempo, por mi madre, con la que él no hablaba y no hablaría más?

Mi carrera como escritor no fue mucho mejor que la suya. Me alcanzó para mantenerme lejos de mi país durante largos y felices años, firmar los ejemplares de algún lector entusiasta y dejar fuera de la vista, hasta hace no mucho, una idea espesa y un tanto cursi sobre la muerte.

Un sueño mío porque no existes, nunca lo has hecho, ninguna cosa; recordarás las palabras sin nada debajo, los gestos de desesperación de la gente que lucha por no despertar del otro lado de las cosas, porque no existen tampoco y es tan horrible, finalmente puedes olerlo, es tan horrible el olor de la vida.

Ni siquiera pude intuirlo cuando regresé al Perú a registrar los últimos días de la vida de mi padre. Le sujeté las manos cada vez más frías. Balbuceaba. La enfermera había tomado nota de algunas palabras que le pareció escuchar durante las horas en que lo atendía, y traté de comparar esos nombres, escritos con torpeza en un papel dormido sobre la mesa de noche, con lo que le escuché decir al viejo en sus instantes finales. Pero no tuve éxito. No logré entender nada. 


\section{CABAÑA Y BOSQUE}

The human body and human behavior are imperfect expressions of personhood, and we are imperfect interpreters.

David Velleman

La recogí muerta para disecarla en una figura que coronara mi estudio. Tuve suerte de encontrarla entera, con la cabeza casi intacta. Había planificado la cacería con una precisión obsesiva. Al llegar al claro, sin embargo, solo tuve que notar el cuerpo recostado entre la hierba para saber que esta vez habría trofeo sin una contienda. La tomé en mis brazos y la llevé con cuidado hasta el auto.

En medio del camino, para mi sorpresa, empezó a moverse, quizás tras sentir el calor de la máquina. Antes de que pudiera sonreírle a ese modesto milagro, me saltó al cuello, enfebrecida por la energía equivalente a la de dos bestias como ella. Apenas pude reducirla sin estrellar el carro contra alguno de los árboles que se agitaban impasibles a los lados de la carretera.

En casa ordené sus cabellos, limpié y remendé su piel a cambio de más arañazos y mordeduras.

Me odiaba, la alimenté con leche fresca y frutos secos, y me siguió odiando. Pero no se atrevía a huir. La visión del bosque a través de las ventanas frenaba su violencia como no lo hacían mis cuidados ni mis palabras.

En poco tiempo se restableció por completo y adoptó una rutina que un observador externo podría calificar como la propia de una mascota. Yo, en cambio, sentía cada uno de los centímetros que guardaba con gélida distancia, y sus evasivas absolutas cuando ella por fin había satisfecho sus apetitos con lo que buenamente le proporcionaba.

Algunos días de lluvia y relámpagos pasábamos tiempo juntos, muy a su pesar, y así le enseñé a leer con una esperanza, con una imagen en mente: yo era un viejo exhausto que no se podía parar de la cama y ella, con una voz dulce, acaso ablandada por la prosa del texto, repasaba páginas al pie de mi lecho.

Me adormecí sobre ese ideal con torpe ingenuidad. Las letras no conjuran el odio. Con un refinado vocabulario como espada, pasó de las dentelladas a los insultos, al menosprecio, al silencio hecho de palabras no dichas que por su cuenta ella había aprendido a callar. Se las agenció para armarse con lo que yo más amaba en la vida, los libros, y hacerme sentir un hombre solo y desgraciado. Astuta, vilmente, prefiere 
sostener esas maneras antes que matarme por las noches, ahora que ha crecido y puede, ahora que es una fiera perfecta y espera que yo cometa la imprudencia de acercarme un poco más de la cuenta. Sé bien que ella no necesita demasiado para darle curso a ese instinto suyo que, enredado con la obvia gratitud que me debe, la tortura durante los días y las noches.

A veces, cuando quedo fuera de mis límites, pienso que en medio de donde estamos nada me cuesta usar una escopeta. Pero ese no soy yo. Yo soy el que dice: solo tiene miedo. Y es muy probable que sea cierto, es probable que yo sea el único pedazo de ese bosque, que aún hoy entre sueños la acosa, del que no puede escapar aquí en casa, donde todo lo demás está dispuesto para su felicidad.

Basta un abrazo para confirmarlo. 


\section{LA ENFERMEDAD MORTAL}

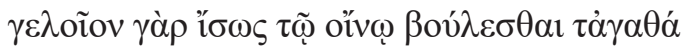

Eth. Nic., VIII, 1155b-30

Mi mujer empezó a enfermar a partir de nuestro segundo año de matrimonio. Se le hundieron las mejillas, sus ojos miraban enrojecidos cuando le sobrevenían las fiebres y los temblores. Al mes más o menos de empezada la calamidad, tuve que comprarle varios dientes falsos y un juego de pelucas, negociar con el seguro la necesidad de una enfermera al menos para las horas de la mañana, luego de hablar seriamente con el doctor al que había llamado por el aspecto de mi esposa, mi querida esposa que cada día me preocupaba más. La noticia no tuvo nada que ver con la muerte. Pero el viejo doctor movió la cabeza, se encogió de hombros, recetó vitaminas y una dieta especial, y me compadeció con la mirada, a lo mejor demasiado, aquella vez antes de despedirse y dedicar su pobre elocuencia a un puñado de palabras de aliento.

¿Por qué?

El camino sería largo.

No me hacía falta nada de eso; igual toleré sin contratiempos su falta de delicadeza. Me habría gustado ser algo más explícito. Podría haberlo explicado todo muy bien.

En lugar de eso dije cualquier cosa. Esa era la conclusión. Estaba parado, firmemente, sobre alguna de sus premisas. Pero esa era la conclusión y era inevitable.

Yo había tenido sueños sobre el matrimonio, había comprado un auto antes de comprometerme con Clara y había hablado de sueldos presentes y futuros durante las dos horas que duró la cena donde la pedí, sosteniendo la mirada encendida del que sería mi único suegro. Mes a mes, además de dinero, había juntado también las fuerzas para hacerme la promesa de que sería feliz y la haría feliz. Me creyeron y yo cerré el capítulo de las manifestaciones públicas de amor. Para mí se trataba de una dicha en voz baja, de una paz mineral. Ella no tenía por qué saber cuán extraordinaria sería nuestra vida juntos. Respetaba mucho mi manera de ser.

La enfermedad fue una confirmación, en la medida en que fue un reto que estiraba y encogía la felicidad. Hasta cierto punto, puso las cosas en su sitio un día sí, un día no. En mi trabajo se enteraron sin que yo se lo contara a nadie y algún mejor amigo me ofreció, cómicamente, su apoyo en todo lo que necesitara. Tuve que reprimir una 
carcajada; a todos por igual les devolvía una sonrisa. No debía quedar ninguna duda sobre mis afectos. Mi rendimiento no decayó lo más mínimo ni entonces ni después.

- Hoy me felicitó mi jefe - le contaba a la enferma al entrar en su habitación y orillarme a su lado; ella asentía despacio para que continuara hablando-. Dice que si sigo así...

O:

—Estoy molido, pero contento. Ha sido un día provechoso...

El dinero alcanzaba para todo, comida, medicinas, ropa, mantener las cosas limpias y en su sitio, y sobraba una parte nada desdeñable que fui juntando con indiferencia antes que con esfuerzo. Era un buen empleado. La verdad: no teníamos que ahorrar para viajes porque ella no podía abandonar la cama, salvo para dar leves caminatas en un parque cerca de casa donde las aves eran pequeñas y rojas; las miraba hechizada. No teníamos que mantener hijos porque alumbrar tan solo uno la habría matado y, por lo tanto, no tenía que buscar una casa más grande a la cual mudarnos para acomodar a tres, cuatro o cinco miembros, ni era necesario ese jardín donde uno imagina que los niños se persiguen unos a otros o a los perros, que desde luego tampoco eran necesarios. En el futuro, todas las casas tendrían el tamaño de una o dos habitaciones y el mismo olor de agua de flores e incienso; nosotros vestiríamos solo ropas modestas: sin viajes ni salidas, aquellos trajes con los que iba al trabajo y los vestidos de cama algo surtidos para ella bastarían. La criada los lavaba muy bien y su diligencia y cuidados mantenían los colores de las telas como nuevos. Una buena mujer que ayudaba sin añadir puntos o comas.

Así pues, la vida frugal que resultaba de ser el modesto acompañante de una enferma compensaba los altos costos del tratamiento (las cosas se habrían complicado un poco si también hubiera caído enfermo de lo mismo o de algo pecuniariamente parecido; mi salud, sin embargo, aun hoy es de hierro).

Con el transcurrir de los años y el desfilar de los impertinentes que nunca cejan cuando huelen los humores del agua estancada, me acostumbré a despacharlos con frases hechas, lugares comunes que bien dispuestos sugerían que mi mujer, más que enferma, estaba mal de la cabeza. No lo decía directamente, pero cualquier persona con algunas luces lo habría pensado al oírme acotar mucho mejor, pero se ha acostumbrado a la cama y en cualquier caso hay que evitar incomodarla. A veces incluso ensayaba pequeños guiones que yo mismo componía durante largas noches abroqueladas por el insomnio. Las visitas, desde luego, menguaron y se redujeron a unos pocos familiares cercanos que podían comprobar que la enfermedad era real, tan real como el cuerpo de mi mujer cada vez más delgado, como el tono de su piel que, por no lograr empalidecer más, se había recubierto de un brillo como de huesos pulidos. 
Ellos también dejaron de venir y así estuvo bien.

(Seguramente se preguntan qué ocurría con eso. Tenía que esperar a que se durmiera. Ella en cierto sentido estaba consciente de lo que ocurría. No era ningún tipo de abuso. No podía serlo. Su sueño era ligero y yo sabía que se despertaba apenas yo empezaba a alistarme. Lo vivimos así hasta el quinto año de su enfermedad. Luego perdí las ganas. Creo que empecé a escribir literatura a raíz de ese revés de mi organismo. Primero poesía, luego cualquier cosa que yo seguía llamando, para no hacerme problemas, poesía. A ella le gustaba que le leyera, aunque también en ese caso tenía que esperar a que la atrapara el sueño. Nunca le revelé que era yo el autor de esos textos).

El tiempo para los enfermos y quienes los vivimos es lentísimo. Si resumo: llegó el día en que ya no podía ser útil para mis superiores, allá en el trabajo. Me lo dijeron con amabilidad y yo lo acepté con la frente en alto. Cada año mis colegas eran más jóvenes y yo más viejo, hasta cierto punto eran demasiado culposos como para hacerme una broma, una última. Me daban las gracias por la vida compartida.

El simple hecho de no ir a la oficina, de carecer de un regreso estilizado durante las noches complicó un poco mi vida matrimonial. Con más tiempo en casa, la enferma o, mejor dicho, la atmósfera, los rituales que habían crecido como mala hierba a su alrededor, me saturaban como nunca lo habían hecho. Empecé a escribir más, casi frenéticamente. Emprendí un poema de diez mil versos, sobre criaturas marinas, que dejé durmiendo incompleto en un cajón y días después destruí, porque el amanecer limpió, tan oportuno, mis ojos de la pátina de la locura. Como profilaxis funcionaba, ahora lo entiendo; pasar las horas garabateando páginas era un lugar, si no para encontrar otro aire, al menos sí para dejar salir el que para ese entonces se empozaba en todas las sombras de la casa.

Un día (noche o madrugada, no lo sé) me rompí la cadera. Regresaba a mi estudio, le había leído el fragmento de una novela triste a mi mujer, la había dejado durmiendo y algo de la conjunción entre su rostro cadavérico y la doble adjetivación de los pasajes más logrados del texto me dejaron absorto, y así, mientras corregía o añadía algo que trataba de sostener en mi mente, no pude ver la pata de una silla y caí. Caí y aullé un nombre o a lo mejor fueron más adjetivos.

Once días después, mi mujer murió.

Mi matrimonio duró cuarenta y siete años, tres meses, más o menos, en total. En sus últimos once días no pude hacer nada por ella. Llegaban hasta donde me encontraba tendido los resuellos de su pecho, la fricción de sus dientes, un hilo de voz que también podía ser el viento que se colaba por entre las rendijas. Una de las piernas me dolía tanto; inflada hasta borrar el rostro de su articulación, me dejó arrastrarme hasta el botiquín donde había guardado viejas pastillas contra dolores que nunca me aquejaron. Las tomé. Me quedé dormido. 


\section{HOMO ECONOMICUS BAJO MÚLTIPLES PRESIONES}

Y viene, de golpe, o aparece, más bien, todo alrededor, y aquí mismo, sin ninguna cualidad, el silencio.

Juan José Saer

—Cuál es tu sueño.

Cuando el doctor pregunta parece mantenerse a flote. La respuesta es la piedra que se clava en la transparente superficie del agua:

-No tengo ningún sueño.

Segundos después, el silencio se vuelve agradable.

- Los tienes. Como todos.

Como todos. La dicción quirúrgica lo libra por muy poco de la intrascendencia.

-Sí.

Ahora se están mirando.

-Entonces.

-Me avergüenzan. Todos mis sueños me devuelven una imagen horrible de mí mismo.

El doctor dibuja esa imagen en el cuaderno (véase el anexo con los bocetos).

-Prefieres ignorarlos.

La verdad sea dicha:

-Prefiero ignorarlos.

— ¿En tus sueños eres grandioso?

De un lado para el otro. No queda más que hablar.

- Digamos. Mi madre solía lanzarnos una frase que de alguna manera lo resume todo: "Ustedes tendrían que haber sido felices". Probablemente nunca la dijo así. Probablemente no fue mi madre, sino mi abuela, que nos crio muchos años. Pero es una frase que acaba...

Corte. 
- Sí. Permíteme apuntarla. Tiene algo profundamente depresivo en la base, en la manera como está hecha.

—Lo sé. Dejaba las cosas en una situación incómoda.

-En qué sentido.

Pase.

- ¿Qué era aquello que debíamos convertir inmediatamente en felicidad? ¿La comida que nos daban? ¿Vivir en una casa enorme a las afueras de la ciudad? ¿El hecho de que el chofer nos llevara a donde queríamos, cuando queríamos, tan pronto como queríamos? Uno de mis hermanos solía correr hacia la fogata, durante las noches de playa. No alrededor del fuego, sino directamente hacia él.

—Empiezo a tener una idea. Pero no quiero adelantarme. De nuevo. Cuál es tu...

-Uno de mis sueños... Una de mis más grandes fantasías era casarme con una mujer de ciencias. Una con guardapolvo y todo.

-Ajá.

-En mi fantasía, soy su objeto de estudio.

-Qué es exactamente lo que ella hace contigo.

El aparato del aire acondicionado empieza a ronronear. Se dedican a escucharlo.

-Nada extraño. Simplemente vive estudiando mis movimientos, renovando su fascinación solo con el examen de mis maneras cotidianas.

El doctor se queda en silencio. ¿No le parecía hermoso?

-No. Pero tampoco horrible.

Después de una pausa:

- Me preguntaba cómo entender a esa científica en función de la mujer de su relato.

El relato al que se refiere el doctor:

Un día de verano vacacionaba en una casa de playa. Estaba bebiendo licor en la terraza cuando vio que un niño de unos tres años aparecía caminando solo por la vereda del otro lado de la pista que separa de la arena las fachadas de las casas del balneario. Entendió que el niño era parte de la población permanente. No entendió cómo había llegado solo hasta allí ni hacia dónde se dirigía. No estaba seguro de que un niño de esa edad pudiera orientarse sin dificultades de un punto a otro del pueblo. Esa inseguridad provocó que se sintiera estúpido. ¿Cómo podía ignorar algo tan elemental?, ¿cuántos otros mecanismos básicos sobre el funcionamiento del mundo permanecían lejos de su 
entendimiento? La palabra termodinámica refulgió en su mente. El licor empezaba a recalentarse. Trató de llamar la atención del niño, primero con torpes saludos y luego con gritos, pero este no interrumpió su deambular durante mucho tiempo. Salvo por esa breve pausa, no dio señales de haberlo escuchado. No le quedó más remedio que abandonar la terraza. En el relato original, insistiendo en detalles bastante retorcidos, cuenta que mientras corría imaginó que un perro atacaba al niño - había muchos perros callejeros sueltos en ese balneario, incluso agrupados en manadas de seis o siete integrantes - y que un extraño en una moto se lo llevaba. O se llevaba el cadáver. Pero, cuando por fin cruzó la pista, vio que el niño estaba solo unos metros más allá, despreocupado e intacto. Miró hacia los lados en busca del adulto que no había encontrado desde la terraza, sin éxito. Ni siquiera el licor le permitió interactuar distendidamente con el pequeño. Quizás le preguntó su nombre. El niño lo miró sin curiosidad. En un momento lo tenía tomado de la mano y, aunque no utilizó la palabra arrastrarlo, es seguro que lo hizo, que jaló al niño hacia la casa donde hasta hace no mucho estaba pasando un rato agradable. ¿Qué habría ocurrido si la madre no aparecía? La historia termina con esa pregunta. La madre, agachada, estaba ocupándose detrás de unos arbustos que forman un cerco irregular al lado de las veredas del balneario. Él lo supo mientras dejaba ir al niño, miraba a la mujer y apretaba el vaso de licor que en ningún momento había soltado. Se bebió todo el contenido restante de un solo golpe. Estaba caliente.

-No veo ninguna relación.

-En la superficie.

— ¿Por qué no podría reconocerlo abiertamente?

El doctor siempre le había dado una interpretación sexual a la expresión sin pelos en la lengua.

-No lo sé. 


\section{PERFILES DEL FIN DEL MUNDO}

Some trainers say that in order to understand your breed, you have to imagine what their voices would sound like and what they'd say to you when you give them a command.

Laurie Anderson 1

El nuevo tiene algo de país polar. Su obsesión por la eficiencia lo vuelve más estable que un líder clásico, animado sobre todo por el éxito y sus estelas. Es difícil confiar en alguien que piensa que lo que no obliga a invertir dinero es superior a aquello que sí lo hace, aunque ambos productos compartan la misma calidad. No pienso extenderle la mano. No pienso darle mi nombre. No sabe quién soy, pero yo sé bien quién es él.

\section{2}

Una pregunta básica para conocer a las personas: de dónde proviene su flexibilidad y de dónde su inflexibilidad. Todos manejamos ambos perfiles en mayor o en menor medida: dejamos que algunas cosas pasen, pero otras han dejado de ser ásperas para ser sencillamente inarticulables. Esos límites, aquello que podría llevar a las personas más allá de sí mismas para bien o para mal, son siempre los demás, alguna forma en la que los etiquetamos. Barreras férreas y también puntos donde el pie se puede hundir con mucha facilidad. Establecerlos es un asunto delicado. Lo sólido se puede volver ajeno, y lo blando, absorbernos. Digamos que es como plantearse el objetivo de conocer de qué está hecho un animal vivo observando el espacio que queda entre los órganos y la piel.

Conclusión provisional: faltan minutos de observación.

3

Es decir, se ve que hay condicionamientos fuertes, pero no sé qué tipo de espíritu anida allí en términos generales, fuera del que yo representaría mediante un arma punzante para lidiar con las superficies escarchadas o una máquina eléctrica que genera un ambiente, un ritmo imposible para las contemplaciones por lo ornamental, la pausa y el ocio. 
Desde luego, no me prefiero a mí ni a mi productividad, que siempre parece al servicio de una cadencia provisional. No pienso aporrear las puertas de la posteridad como si detrás hubiera un urgido sanitario de oro. ¿Oro para qué, si no es para comprar tiempo? Somos un peligro para nosotros mismos.

\section{5}

Es decir, nerviosos, minúsculos, enclaustrados en alguna idea redentora, pero teledirigida por la sombra de un mundo que consideramos, en principio, amenazador y, bien visto, es solo el reverso del inalcanzable paraíso hacia el cual tendemos. Por esa tímida insinceridad preferimos los atajos de la imaginación, la fantasía tan difícil de crear a gran escala y sin fisuras, sin filtraciones, pero, una vez que está más o menos lista, que es más o menos acogedora, es también mucho más fácil de habitar.

\section{6}

El nuevo ha venido a revisar mi lugar.

Me mira a los ojos, aunque en ellos solo caben las pocas cosas que aún duermen en mis cajones.

Con un artificial ritmo pausado, las coloco en la única caja que me llevaré a casa. No me despido. Simplemente me voy. 


\section{ORILLAS}

Camino por la orilla de una playa desierta, impasible como la mañana y casi tan fresco. Llegué con los ojos cerrados; esa ceguera relativa me protege, al principio, del sol. El mar sugiere de a pocos ideas que descarto: la masa de agua y su vaivén perfilado son por el momento suficiente compañía. Prefiero, en todo caso, mirar mis pies, no puedo evitar mirarlos. Cada una de las huellas que las aves traspasan sin curiosidad. Avanzo sabiendo que juntas dibujarán la ruta interior del alba.

Así continúo hasta que, fulminado por un instante de brillo cenital, noto que en el lugar que le corresponde al siguiente paso una piedra duerme un sueño más antiguo que el mío. La levanto, la examino, la dejo secar como si le procurara un favor. Es una piedra gris y anónima a la que el tiempo del mundo ha lamido hasta volverla esencial.

Bastante común es la acción de tropezar con una piedra en la playa, pero esa rutinaria constatación no detiene la historia: lo gris, lo áspero, lo tibio en considerable equilibrio han logrado en la palma de mi mano el peso exacto de un animal pequeño.

Guardo la piedra en el bolsillo y sigo andando el paisaje durante un tiempo que se escapa del tedio y pronto también de la fatiga.

No muy lejos, encuentro semienterrada otra piedra. Es idéntica a la primera.

Comprometo un esfuerzo deliberado para hallar las diferencias, en vano. Examino, limpio, sonrío y guardo en el bolsillo, esta vez con la idea, la vaga esperanza, de que la primera me llevó a la segunda y de que seguramente esta me llevará a una tercera.

Unos metros más allá, efectivamente, la tercera piedra.

Y luego, donde las espero, una cuarta y una quinta...

Los bolsillos llenos de piedras. El sol arde sus últimos destellos anaranjados. Pesan.

Atino a mirar hacia atrás recién cuando estoy a punto de ceder y cada nuevo paso me entierra las piernas.

Alguien debe de haber dejado esas piedras a propósito, pienso. Digo, apenas despierto:

-Estoy deshaciendo un camino. 


\section{RECOSTADA (DÍA AL REVÉS)}

Aunque mi día comienza conmigo, siempre, como el de todos, hoy estuve unos instantes detrás de él. Me había propuesto una rutina férrea, doblegar mis vacaciones en el final del año que se anuncia sin vergüenza y en la mentira del año entero de doce meses de impuros trámites. Juzgando la posibilidad de un orden modesto, pero simétrico y constante como la gestación de la lluvia, y amenazando mis subversiones con alguna sinuosa consecuencia moral, con esa verdad, dura, triste, que es la culpa, para mantenerme en-un-aquí-y-en-un-ahora de diario adolescente, permití, atenta y confusa, el rigor de una página en blanco finalmente tachada por nombres que pretendían contener lo que desde hacía mucho había dado por perdido: experiencias. Qué flagelo. Constantemente. Y eso a pesar de la oposición de las demás partes de mi cuerpo - unidas en el gran gremio del cuerpo, digamos: toda voz está excluida de ahí- que no pierde la oportunidad de demandar justicia con la forma de sus órganos. Mi día así aligerado me dejaba atrás: en la orilla de la cama, después sobre mis pantorrillas, después a la mesa, después con la pastilla viajando, después, casi inconsciente midiendo el ancho de lo que me acogía, una mañana de sol tentador - mi brazo se quemó fuera de la ventana del auto, las cosas fueron por momentos claras a mis ojos; es bueno que mi padre sea siempre el que maneje-, un libro abierto y luego cerrado, después, siempre y solo después, el día que ahora recuerdo sin más, que ahora se deja manosear para qué, hasta cuándo, no sé cómo. 